\title{
Advances in Pressure Swing Adsorption for Gas Separation
}

\author{
Carlos A. Grande \\ Department of Process Chemistry, SINTEF Materials and Chemistry, P.O. Box 124, Blindern, 0314 Oslo, Norway \\ Correspondence should be addressed to Carlos A. Grande, carlos.grande@sintef.no
}

Received 25 September 2012; Accepted 18 October 2012

Academic Editors: T. M. Aminabhavi, D. Cazorla-Amoros, and X. Feng

Copyright () 2012 Carlos A. Grande. This is an open access article distributed under the Creative Commons Attribution License, which permits unrestricted use, distribution, and reproduction in any medium, provided the original work is properly cited.

\begin{abstract}
Pressure swing adsorption (PSA) is a well-established gas separation technique in air separation, gas drying, and hydrogen purification separation. Recently, PSA technology has been applied in other areas like methane purification from natural and biogas and has a tremendous potential to expand its utilization. It is known that the adsorbent material employed in a PSA process is extremely important in defining its properties, but it has also been demonstrated that process engineering can improve the performance of PSA units significantly. This paper aims to provide an overview of the fundamentals of PSA process while focusing specifically on different innovative engineering approaches that contributed to continuous improvement of PSA performance.
\end{abstract}

\section{Introduction}

Adsorption is the name of the spontaneous phenomenon of attraction that a molecule from a fluid phase experiences when it is close to the surface of a solid, named adsorbent. There are several pristine works that explain this phenomenon in detail [1-18]. Adsorbents are porous solids, preferably having a large surface area per unit mass. Since different molecules have different interactions with the surface of the adsorbent, it is eventually possible to separate them. When the adsorbent is put in contact with a fluid phase, an equilibrium state is achieved after a certain time. This equilibrium establishes the thermodynamic limit of the adsorbent loading for a given fluid phase composition, temperature, and pressure [3]. Information about the adsorption equilibrium of the different species is vital to design and model adsorption processes [19-27]. The time required to achieve the equilibrium state may be also important, particularly when the size of the pores of the adsorbent are close to the size of the molecules to be separated [28-43].

In an adsorption process, the adsorbent used is normally shaped into spherical pellets or extruded. Alternatively, it can be shaped into honeycomb monolithic structures resulting in reduced pressure drop of the system [44-54]. The feed stream is put into contact with the adsorbent that is normally packed in fixed beds. The less adsorbed (light) component will break through the column faster than the other(s).
In order to achieve separation, before the other (heavy) component(s) breaks through the column, the feed should be stopped and the adsorbent should be regenerated by desorbing the heavy compound. Since the adsorption equilibrium is given by specific operating conditions (composition, $\mathrm{T}$ and $\mathrm{P}$ ), by changing one of these process parameters it is possible to regenerate the adsorbent.

When the regeneration of the adsorbent is performed by reducing the total pressure of the system, the process is termed pressure swing adsorption (PSA), the total pressure of the system "swings" between high pressure in feed and low pressure in regeneration $[55,56]$. The concept was patented in 1932, but its first application was presented thirty years later [57].

Over the years it has been demonstrated that PSA technology can be used in a large variety of applications: hydrogen purification [58-72], air separation [57, 7380], OBOGS (on-board gas generation system) [81], $\mathrm{CO}_{2}$ removal [82-84], noble gases ( $\mathrm{He}, \mathrm{Xe}, \mathrm{Ar})$ purification [8587], $\mathrm{CH}_{4}$ upgrading [31, 34, 37, 40, 42, 88-96], n-iso paraffin separation [5, 97-99], and so forth. The PSA processes are normally associated to low energy consumption when compared to other technologies [12, 55, 100-102].

As a rule of thumb, pressure swing adsorption is preferred to other processes when the concentration of the components to be removed is quite important (more than a few per cent). In such conditions, loading the column with 


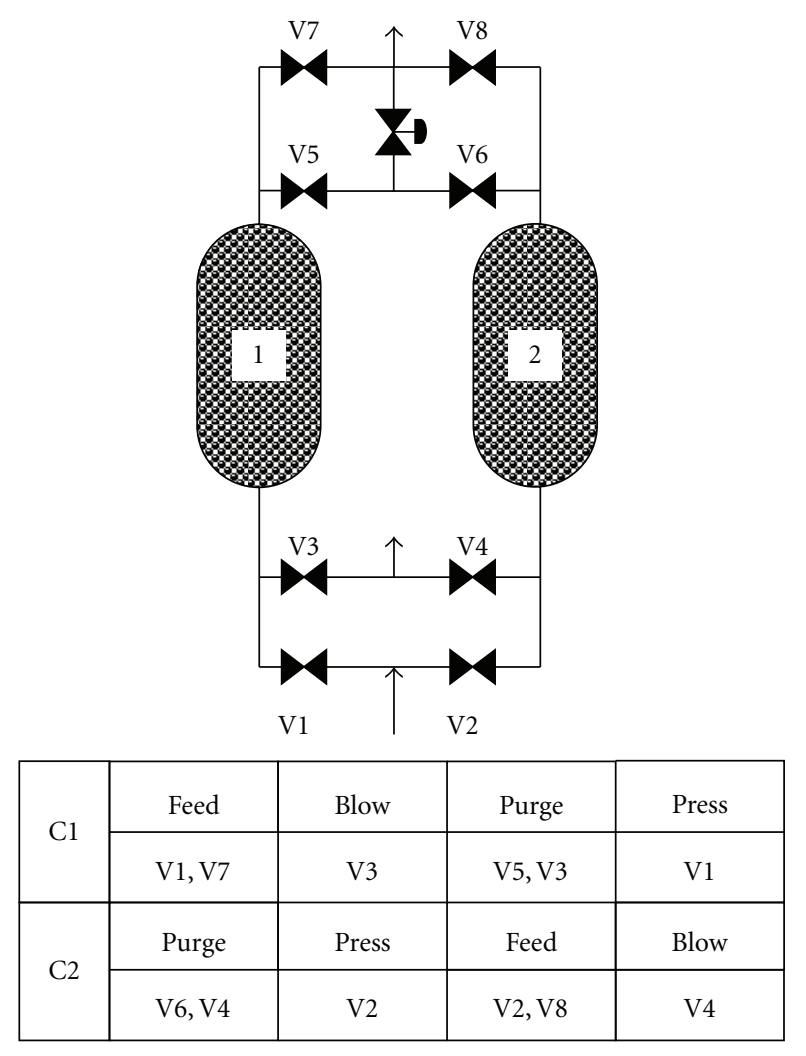

FIGURE 1: Schematic design of the first two-column pressure swing adsorption unit and valve sequencing for different steps in the cycle [1].

the heavy component is accomplished quite fast and since the pressure of the system can be changed rapidly, the time between adsorption and regeneration is balanced. When the concentration is low, the adsorption step may take much longer and other options like temperature swing adsorption (TSA) can be considered [12].

The behaviour of the PSA unit is mainly determined by the adsorbent employed for the separation. However, the engineering of the PSA unit is also an important aspect. In fact, the main task of defining a PSA unit is to select correctly the adsorbent to be employed [103]. After that, all the engineering efforts should be placed in defining an effective strategy to regenerate the adsorbent. Thus, the advances obtained in PSA units can be divided in two main domains: the discovery of new adsorbents (material science) and new and more efficient ways to use and regenerate the adsorbent (engineering).

This work provides an overview of PSA processes and its evolution on time. The most important industrial applications of PSA processes will be used to address its technological evolution: air separation and hydrogen purification. A growing market of $\mathrm{PSA}, \mathrm{CH}_{4}-\mathrm{CO}_{2}$ separation, will also be used for some specific examples. Although it is not intended to describe the state-of-the-art of materials science, an example of the effect of different adsorbent materials in PSA operation will be provided. Finally, the effect of different regeneration protocols and the reduction of the overall cycle time (Rapid Pressure Swing Adsorption) are discussed.

\section{Fundamentals of Pressure Swing Adsorption}

The essential feature of the PSA is that when the adsorbent is saturated, using a sequential valve arrangement, the feed is stopped and simultaneously the total pressure of the column is reduced. The reduction in pressure results in a partial desorption of all the species loaded in the column, "regenerating" the adsorbent. Since this process was patented after TSA, it was initially known as "heatless" process. The first patent application where PSA technology was described, was presented by Charles Skarstrom for oxygen enrichment [57]. A scheme of the two-column PSA introduced in that patent is shown in Figure 1. In order to operate such unit cyclically, a column experiences a series of "steps": events like opening and closing valves and changing flowrate direction for example. The sum of all the steps is termed as "cycle". Even when the process is unsteady, after some cycles it reaches a Cyclic Steady State, CSS. When CSS is achieved, the performance of the cycles of the PSA is constant over time. It should be noted that since this process sometimes involve substantial amount of heat generation, there can be multiple CSS [104].

The four steps of the "Skarstrom cycle" are also shown in Figure 1: feed, blowdown (or evacuation), purge and pressurization. In this cycle, in the feed step, air is fed to the first column (C1) at a pressure higher than atmospheric. The adsorbent initially used (zeolite 5A) is selective to nitrogen, making the exiting stream (after valve V7) richer 
in oxygen. When the adsorbent packed in $\mathrm{C} 1$ is saturated and cannot adsorb more nitrogen, the feed is directed to the second column (C2). In order to release part of the nitrogen adsorbed in $\mathrm{C} 1$, the flow direction is reversed and the total pressure of the column is reduced by venting to atmosphere (opening valve V3). There are different terms to call this step, but blowdown is one of the most common and will be used here. In the blowdown step, nitrogen is desorbed from the adsorbent and released and at the end of this step, the gas phase inside the column is rich in nitrogen. To additionally remove nitrogen from the column, a purge step (or light gas recycle) is used. The purge consists of recycled part of the enriched air from the other column which is flowing by the pressure differential between the two columns. After the adsorbent is ready to load more nitrogen, the overall pressure of the system should be restored. That is done in the pressurization step using the feed stream. After all these steps were finished, a complete cycle was completed. It is important to notice that although the column operation is discontinuous, the feed stream is being employed so the process can be viewed as continuous. However, the exit is discontinuous and a tank is required to be coupled for a continuous discharge. Also, the operation in both columns should be synchronized to satisfy the continuous utilization of the feed and to provide purge gas to the other column.

The requirement of continuous feed processing, even being a discontinuous process, was recognized, since one of the first inventions of adsorption processes [105]. Furthermore, the valve arrangement for sequential opening - close and step definition was also very similar to designs presented for TSA processes [106]. However, the contribution of Skarstrom allowed a tremendous improvement in utilization of the adsorbents: while TSA cycles last for several hours, the PSA cycles are much shorter and thus using more adsorbent per unit time.

Another important aspect of a PSA process was mentioned in Skarstrom's application: heat effects and conservation. In the adsorption step, heat generated by adsorption may be important in which case the temperature of the column changes with time and also with position $[4,5,55]$. The consequence is a reduction in the adsorbent capacity. The "heat effects" may be very important in designing a PSA unit [107] and should be taken into account in the design: laboratory or small-scale experiments are either isothermal or close to isothermal and the heat capacity of the wall is important while large-scale processes behave adiabatically. In the desorption steps, the opposite is happening: energy is required for desorption resulting in a temperature decrease enhancing the potential capacity of the adsorbent and making desorption more difficult. This will happen in all PSA applications but in some cases, the amount of heat generated is not so important and the process can be considered isothermal. Every time there is a temperature swing associated to the PSA cycle, the performance is worse than what would be if the cycle is isothermal. However, since the thermal effects are present, it is good practice to conserve the "heat wave" inside the column: this heat will be used for a faster desorption.

\section{Modifications to the Skarstrom Cycle: New Cycle Steps}

In the years after Skarstrom invention, there were several patent applications to improve the cycle. In a patent that was filled almost at the same time as Skarstrom, the regeneration under vacuum was introduced by Guerin de Montgareuil and Domine [73]. When vacuum is used for regeneration it is common to term the unit as vacuum pressure swing adsorption (VPSA). Although the utilization of vacuum may have an impact on the energetic requirements of the system, the efficiency of the unit may be greatly improved if the loading of the most adsorbed components changes dramatically at pressure lower than atmospheric. In the same invention, the authors have introduced the utilization of the pressurization step using part of the enriched gas. The utilization of a pressurization using part of the purified gas had impact in the purity of the produced gas [108]. Even when using the same pressure swing concept, the alternatives to develop the PSA technology are quite diverse, opening the "PSA engineering" possibilities.

The introduction of a pressure equalization step was developed at ESSO Research group [74, 109, 110]. Taking the two-column PSA scheme from Figure 1, after C1 ends the feed step (and is at high pressure), C2 ends the purge step (and is at low pressure). In that moment, V5 and V6 are simultaneously opened, short-circuiting the columns. This means that part of the gas that will normally get lost in the blowdown step is being used to pressurize the other column, loosing less purified gas. If the gas moving from one column to the other is not significantly adsorbed (e.g., hydrogen) the pressure achieved after the equalization step is the geometric average between these two values. The overall pressure can be lower if the gas transferred is fast adsorbed [111]. The result of the pressure equalization step is a direct improvement in the recovery of the light product $[112,113]$. The introduction of a pressure equalization step in a 2-column PSA unit results in a significant change of the "continuity" of the process. When the two columns are in pressure equalization, there is no feed processing so at least one more column is required [110].

When several columns are employed, several pressure equalization steps can be done [114-116] and as a consequence, the overall recovery is increased $[65,117,118]$. This finding resulted in the design of multiple column (Polybed) PSA units [65].

Another possibility to remove part of the light component from the column before blowdown is depressurizing the bed co-currently to the feed direction. This step is very useful in hydrogen purification and is normally termed as "provide purge" step since it provides gas for purging other column [119].

Co-n-current depressurization was also used to remove the less adsorbed gas from the column in order to increase the content of most-adsorbed gas inside the column (aiming to its concentration) [32, 120-122].

An interesting concept of column depressurization is provided by the unique availability of "free vacuum" obtained in outer space [123]. In order to have a faster 


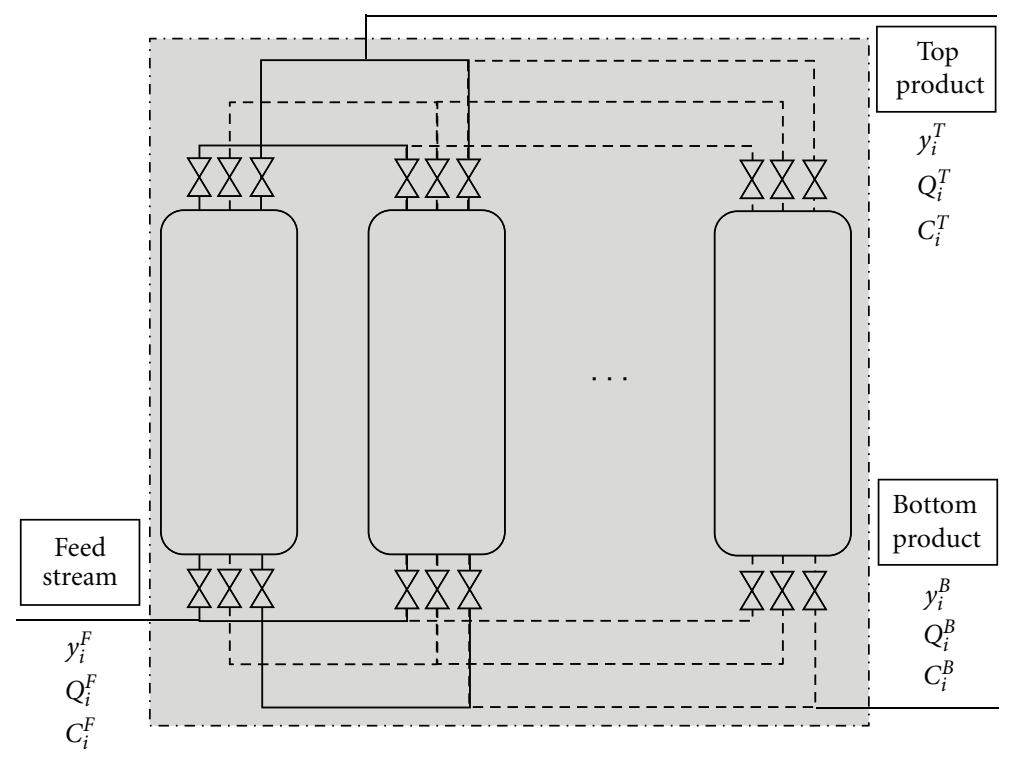

FIGURE 2: "Grey-box" generic example of a pressure swing adsorption (PSA) process. The inlet and exit streams are characterized by molar fraction $\left(y_{i}\right)$, volumetric flowrate $\left(Q_{i}, \mathrm{~m}^{3} / \mathrm{s}\right)$, and gas concentration $\left(C_{i}, \mathrm{~mol} / \mathrm{m}^{3}\right)$.

depressurization, it was proposed to open the column from both ends to release the gas faster. Parallel equalization using valves at different column lengths were also suggested [124]. Using a low-pressure feed as a purge was also suggested to increase the purity and recovery when compared with the Skarstrom cycle [125]. For the case of separation of a ternary mixture, feeding and one product withdrawal in intermediate positions of the column was also suggested, with a PSA design resembling the Petliuk scheme for distillation [126, 127].

In order to displace the light component to the product end, a recycle of the heavy component was suggested by Basmadjian and Pogorski [128]. This step was called "rinse." Although the rinse step aimed to provide a solution to concentration of low-per cent light compounds, it has been widely used for other purposes: concentration of the more adsorbed species [32, 120-122, 129-132].

In fact, the number of possible "steps" is not very large. However, using them in an efficient way has proved to be a difficult task. So far, the question raised by Professor Ruthven in 1992 was not yet completely answered [133] ("Is it possible to develop an algorithm for automatic generation of PSA cycles and tuning of the various steps?").

\section{Performance Indicator Parameters of a PSA Process}

So far, it has been shown that PSA processes have a tremendous flexibility in design (so large that sometimes is misleading). A completely different number of columns can be used and also a quite large number of cycles are possible. In order to provide a certain "common framework" to understand some aspects of PSA engineering, it is desirable to have some "performance indicators" (PI) which will be the ones that will define how well performs the PSA
TABLE 1: Performance indicator parameters for a PSA process.

\begin{tabular}{ll}
\hline $\begin{array}{l}\text { Less-adsorbed gas is the } \\
\text { product }\end{array}$ & More-adsorbed gas is the product \\
\hline Purity $=\frac{C_{i}^{T}}{\sum_{i=1}^{N} C_{i}^{T}}=y_{i}^{T}$ & Purity $=\frac{C_{i}^{B}}{\sum_{i=1}^{N} C_{i}^{B}}=y_{i}^{B}$ \\
Recovery $=\frac{\int_{0}^{t} C_{i}^{T} Q_{i}^{T} d t}{C_{i}^{F} Q_{i}^{F}}$ & Recovery $=\frac{\int_{0}^{t} C_{i}^{B} Q_{i}^{B} d t}{C_{i}^{F} Q_{i}^{F}}$ \\
Productivity $=\frac{\int_{0}^{c_{\text {cycle }}} C_{i}^{T} Q_{i}^{T} d t}{X w_{\text {ads }} t_{\text {cycle }}}$ & Productivity $=\frac{\int_{0}^{t_{\text {cycle }}} C_{i}^{B} Q_{i}^{B} d t}{X w_{\text {ads }} t_{\text {cycle }}}$ \\
\hline Energy = sum of all compression and vacuum sources used
\end{tabular}

process. For the definition of such parameters, the PSA process depicted in Figure 2 can be considered. The image shows a PSA process with $X$ columns ( $X$ can also be unity) accommodating a specific mass of adsorbent per column $\left(w_{\text {ads }}\right)$ and with multiple connection lines to accommodate very different steps. The objective is to separate component $i$ from $N$ components and two cases may be found: either the purpose of the PSA is to purify the less adsorbed gas or alternatively, to concentrate the more adsorbed gas.

The most common PI found in PSA processes are listed in Table 1 [134]. The two first PI (purity and recovery) are related to the separation efficiency of the PSA and normally establish the $\mathrm{GO} / \mathrm{NO} \mathrm{GO}$ condition in process design. If such specifications are satisfied, the "fingerprint" of the unit is evaluated by the productivity. Finally, the energetic considerations should be made. Since the process is so flexible, it is difficult to define an energetic PI other than saying that is the sum of all work used for compression and vacuum. Note that the recovery and productivity have an integral term that is mainly due to variations in flowrate in the exit streams. 
Most works on PSA processes have shown that normally the purity and recovery present a trade-off for the design. In the case of recovering the less adsorbed gas, if more purge is used, more of the contaminants can be desorbed from the column and purity increases, but since more light gas is exiting from the "bottom end," light-gas recovery is smaller. A similar effect is observed for the utilization of the rinse step and purity and recovery of the more adsorbed gas.

However, other strategies are valid to improve process recovery without seriously affecting the purity. The case of Polybed PSA for $\mathrm{H}_{2}$ purification is a good example [65]. The units built until 1975 were having 4 columns and the recovery of $\mathrm{H}_{2}$ was around $60 \%$. Nowadays, PSA unit with 12 columns are found [65] and up to 16 columns were patented [135] with $\mathrm{H}_{2}$ recovery close to $90 \%$. When the number of columns is increased, more pressure equalization steps can be performed and thus less hydrogen is lost with the contaminants, increasing its recovery.

The developments in the PSA process presented above were mainly motivated to improve the purity and the recovery of the target product(s). Nowadays, several new applications of PSA as an alternative technology are still in the stage of finding proper cycle configuration (step scheduling and times, number of columns, etc.). Other applications in more established markets are intending to improve either the unit size and/or the energetic consumption of the separation.

\section{The Role of the Adsorbent in PSA}

The development of materials science in the last 60 years was quite intense. The result was the discovery of many porous materials, from all kind of zeolites and mesoporous materials [136-141] to the most diverse surfaces in activated carbons [142-145] and lately the high-surface area coordination polymers [146-151]. However, as strange as it may seem, only few materials are used in PSA units nowadays.

A review of adsorption properties of the different materials is out of the scope of this work, but good databases with adsorption properties of different gases on several adsorbents can be found $[16,152,153]$. What is important to mention is that a material to be used in PSA should be easily regenerated. It is frequent to find in literature adsorbents with a very high capacity, particularly at low pressures. Normally the isotherms of gases on such adsorbents are "rectangular": very steep at low pressures and quite flat after a certain pressure. Defining the "cyclic capacity" as the difference of loading between the high and low pressures of the PSA cycle, the only way to have an acceptable cyclic capacity is making blowdown at very high vacuum. The direct implication of using such conditions is that the power consumption increases rapidly. So, materials showing linear or slightly nonlinear isotherms are preferred in PSA design.

One frequent case is to have a multicomponent mixture of gases and that the number of compounds to be separated cannot be removed by a single adsorbent. The solution to this problem was found for the case of $\mathrm{H}_{2}$ purification from methane steam reforming. In this application, $\mathrm{H}_{2}$ is mixed with $\mathrm{H}_{2} \mathrm{O}, \mathrm{CO}_{2}, \mathrm{CO}$, unconverted $\mathrm{CH}_{4}$, and possibly other gases like $\mathrm{N}_{2}$. Activated carbon can be used to remove $\mathrm{H}_{2} \mathrm{O}$ and $\mathrm{CO}_{2}$ quite selectively but the loading for $\mathrm{CO}$ is rather limited for small partial pressures. It is thus common practice to use different layers of adsorbents to increase the loading of $\mathrm{CO}$ in the same column. This approach has also been applied in other separations $[66,70,79,154-160]$. Consecutive layers of adsorbents can also be used to improve the productivity of kinetic adsorbents by adding a material that can be easily regenerated after the kinetic adsorbent $[161,162]$.

Other important aspect regarding the material properties for PSA applications is the diffusion of the different gases through its porous structure. There are different types of "resistances" to diffuse from the bulk gas phase to the adsorption site $[4,5]$. They are: boundary layer around the adsorbent particle, and resistances in the macro-meso pores, mouth of the micropores, and micropores (or crystals).

In some applications however, these mass transfer "problems" have become part of the solution. In fact, if the diffusional resistance of one of the components of the mixture is very large, this gas will take so long to adsorb that can be separated from other gas that diffuses faster through the pores.

The "kinetic processes" were recognized soon [28]. In fact, materials like zeolites are called "molecular sieves" because of this effect [136]. Another example of kinetic materials is the carbon molecular sieves (CMS) [29-31, $33,38,163-167]$. A CMS is prepared by contracting the pores of an activated carbon to limit the adsorption of some molecules. Its first utilization was for air separation to separate $\mathrm{O}_{2}$ from $\mathrm{N}_{2}$.

An extreme example of resistance to diffusion is the molecular exclusion like in the Isosiv process [5, 97-99]. In the Isosiv process, $\mathrm{n}$-paraffins are selectively adsorbed in zeolite 5A, while isoparaffins are kinetically excluded from the zeolite crystals.

Most recently, several inorganic materials have proved to be useful for kinetic separations [34, 36, 168-173]. A special kind of titanosilicates, ETS-4, cation exchanged with alkaliearth metals can be used for kinetic separations $[35,41,174$, 175]. In these materials, the pore size can be tuned with a very high accuracy by thermal treatment of the sample. Many studies have confirmed that $\mathrm{CH}_{4}$ can be excluded from the structure while gases like $\mathrm{H}_{2} \mathrm{~S}, \mathrm{CO}_{2}$, and specially $\mathrm{N}_{2}$ can be adsorbed $[43,176,177]$.

\section{Advances in Process Engineering}

From all the main advances in process engineering, the most challenging one is the development of cyclic strategies that can improve the performance indicators of the PSA. Despite the performance of the material, the design of a PSA process requires several engineering decisions that should be taken sometimes with a very deep impact in terms of performance indicators. The main drawback of the engineering of a PSA process is that it is quite task consuming (and normally iterative).

With modern computers, the design of the PSA cycle can be carried out by modelling different scenarios. There are different degrees of complexity to define a PSA model, 
normally comprising several partial differential equations linked by the equation of state and the isotherm model to define the thermodynamic properties of the gas and adsorbed phases, respectively. Although the model can be solved by numerical methods [55, 113, 178-183], there are several commercial programs that can be already used for that purpose: ASPEN, COMSOL, gPROMS, PROSIM, and so forth $[18,184-187]$.

The simulation of a PSA process requires an initial step of defining a cycle structure (ordering the steps in a pre-defined sequence) and then estimate the performance indicators obtained. For the selected cycle, all the step times, blowdown pressure, and flowrates of rinse and purge steps should be determined [25, 188-192]. Alternatively, it has been suggested that a general "super-cycle" can be used to estimate the optimal duration of each of the steps [193].

In most cases, the definition of the cycle has to be done under certain constrains like combining it in a multiple column array. Other constraints can result from the availability of gas to the purge step, the continuous utilization of vacuum pump for blowdown, and so forth. The availability of gas to the purge step can also proceed from a depressurization step (provide purge) [119] or from a prestored amount in a tank [194]. A graphical procedure to schedule PSA cycles was suggested [195, 196]. It is also found in literature that in some cases, the best cycle does not match perfectly in a continuous array of columns and thus an "idle" step is used where the column is closed and no effective step for adsorption or desorption takes place. However, the existence of idle periods does result in smaller unit productivity of the PSA unit.

Recasting how the PSA productivity is calculated, we can see the interaction between the influence of process engineering and adsorbent development is mixed. If we have an adsorbent with a better cyclic capacity, we will be able to adsorb more gas per cycle and thus reduce the overall weight of adsorbent (or alternatively, increase the production of gas). On the other side, by better process engineering, we could improve the performance of the unit by balancing the amount of gas produced and possibly reducing the number of columns employed.

Furthermore, there is a third alternative: reduce the total cycle time. This alternative was suggested many years ago [197] and has started been implemented in the 80s [198]. When the total cycle time is smaller than 30 seconds, the process is normally called Rapid PSA (RPSA) $[145,179,198-$ 214].

A typical cycle time $\left(t_{\text {cycle }}\right)$ of a normal PSA process is in the order of 10 minutes. In that time, the adsorbent is used to adsorb and desorb a certain amount of gas. Within each column of the PSA that amount adsorbed will be distributed in an initial zone where equilibrium has been achieved and a "mass transfer" zone close to the end of the column where the adsorbent is not completely saturated. The mass transfer zone is related to kinetic limitations to diffuse into the adsorbent and axial dispersion. Reducing the cycle time will result in more kinetic limitations and thus longer mass transfer zones. However, if reducing the cycle time in a factor of 10 results in a decrease of the amount adsorbed/desorbed in a factor of 2 (by kinetic limitations to adsorb), then the overall productivity of the PSA unit has still increased in a factor of 5. The result is that the PSA unit will be five times smaller!

There are several fields where RPSA can make a complete difference. A PSA for production of medicinal oxygen is a very suitable unit for utilization in hospitals. However, the concept of RPSA has opened the possibility of portable devices with quite small size that can be used for ambulatory patients with chronic lung diseases $[78,215]$. Comparing the productivity of a PSA process to purify hydrogen, it can be noted that is quite lower than the productivity found in other PSA applications. In such a field, the utilization of RPSA concept can lead to significant reduction in size $[201,216]$.

The utilization of RPSA is limited by fluid dynamics. Using the Ultra-rapid piston driven PSA, the total cycle time was less than 5 seconds (its adsorption/desorption cycles resemble the expansion and compression of an internal combustion engine). Under such conditions, the mathematical models used to simulate normal PSA processes may not work $[210,217]$ : mass and energy transfer description using simplifications like LDF (linear driving force) are not applicable. There are also some particularities related to RPSA that could be overcome with the utilization of specialized devices.

In RPSA processes, the time required for pressurization of the bed can be a problem. It has been proven that by using a honeycomb monolith, it is possible to reduce the pressure drop of the PSA process [209] and thus reduce the overall pressurization time. Alternative to monolithic structures, laminated adsorbents have been suggested [218].

The other invention that is directly applicable to RPSA technology is the rotary valve $[205,207,219]$. Taking as example the PSA unit shown in Figure 1, it can be observed that the step changes in a normal PSA are accomplished by the simultaneous operation of a sometimes complex valve array. Using rotary multiport valves, it is possible to change the events taking place in all the columns at the exact same time. Using a normal valve array, a failure of one second in opening or closing one of the valves can have a significant impact in a RPSA cycle.

Another approach to PSA technology was carried out using radial columns [220-222]. Using radial columns, the length of adsorbent is normally small (resulting in decreased pressure drop) and the amount of gas to be treated at a reasonable gas velocity can be higher.

\section{Concluding Remarks}

The great flexibility of PSA is normally associated to process complexity and is still one of the major issues to introduce this technology in several fields of industry. On the other hand, the large flexibility of PSA processes still constitutes its main advantage and may be the reason why it has found applications in diverse fields.

PSA technology can be considered a mature technology in air separation, drying, and hydrogen purification, but there is plenty of work to do to establish this technique in other fields [223]. Many researchers around the world are 
currently working on $\mathrm{CO}_{2}$ capture from flue gases. It has been potentially demonstrated that $\mathrm{CO}_{2}$ can be captured using PSA [224-227] but more fundamental and long-term pilot plant studies are required to properly benchmark this technique against amines. Also, olefin-paraffin separation by adsorption was quite studied, but the energetic consumption of the separation by adsorption is still comparable to distillation [228]. Utilization of PSA for natural gas upgrading $\left(\mathrm{CH}_{4}-\mathrm{CO}_{2}\right.$ separation basically) still also remains a challenge $[229,230]$. PSA technology and even RPSA can be used to upgrade biogas, but the flowrate and pressure levels of natural gas require alternative solutions. Furthermore, new stringent legislation related to reducing the emission of greenhouse gases is changing the design of processes in energy and fuel industries. New processes intend to include or integrate the $\mathrm{CO}_{2}$ capture, thus introducing specifications in the most adsorbed compound. A solution that is already in use and should be more explored is the dual PSA concept [231-235].

In all these emergent applications of PSA technology, faster and better solutions can happen by having a good interaction between materials science and process engineering.

\section{References}

[1] I. Langmuir, "The adsorption of gases on plane surfaces of glass, mica and platinum," The Journal of the American Chemical Society, vol. 40, no. 9, pp. 1361-1403, 1918.

[2] M. Polanyi, "Section III.- - theories of the adsorption of gases: a general survey and some additional remarks. Introductory paper to section III," Transactions of the Faraday Society, vol. 28, pp. 316-333, 1932.

[3] A. L. Myers and J. M. Prausnitz, "Thermodynamics of mixedgas adsorption," AIChE Journal, vol. 11, pp. 121-127, 1965.

[4] D. M. Ruthven, Priciples of Adsorption and Adsorption Processes, John Wiley \& Sons, New York, NY, USA, 1984.

[5] R. T. Yang, Adsorbents. Fundamentals and Applications, John Wiley \& Sons, New Jersey, NJ, USA, 2003.

[6] P. C. Wankat, Large-Scale Adsorption and Chromatography, CRC Press, Boca Raton, Fla, USA, 1986.

[7] A. E. Rodrigues, M. D. LeVan, and D. Tondeur, Adsorption, Science and Technology, Kluwer Academic Publishers, Boston, Mass, USA, 1989.

[8] M. Suzuki, Adsorption Engineering, Chemical Engineering Monographs, Elsevier, Tokyo, Japan, 1990.

[9] J. Kärger and D. M. Ruthven, Diffusion in Zeolites and Other Microporous Solids, John Wiley \& Sons, London, UK, 1992.

[10] C. Tien, Adsorption Calculations and Modeling, ButterworthHeinemann, Boston, Mass, USA, 1994.

[11] D. Basmadjian, The Little Adsorption Book: A Practical Guide for Engineers and Scientists, CRC Press, Boca Raton, Fla, USA, 1997.

[12] J. L. Humphrey and G. E. Keller, Separation Process Technology, McGraw-Hill, New York, NY, USA, 1997.

[13] D. D. Do, Adsorption Analysis: Equilibria and Kinetics, Imperial College Press, London, UK, 1998.

[14] J. W. Thomas and B. D. Crittenden, Adsorption Technology and Design, Elsevier, Boston, Mass, USA, 1998.

[15] O. Talu, "Needs, status, techniques and problems with binary gas adsorption experiments," Advances in Colloid and Interface Science, vol. 76-77, pp. 227-269, 1998.
[16] F. Rouquerol, J. Rouquerol, and K. Song, Adsorption by Powders and Porous Solids, Academic Press, London, UK, 1999.

[17] J. Keller and R. Staudt, Gas Adsorption Equilibria: Experimental Methods and Adsorption Isotherms, Springer, Boston, Mass, USA, 2005.

[18] P. C. Wankat, Separation Process Engineering, Prentice Hall, London, UK, 2nd edition, 2007.

[19] K. S. Knaebel and F. B. Hill, "Pressure swing adsorption: development of an equilibrium theory for gas separations," Chemical Engineering Science, vol. 40, no. 12, pp. 2351-2360, 1985.

[20] M. D. LeVan, "Pressure swing adsorption: equilibrium theory for purification and enrichment," Industrial and Engineering Chemistry Research, vol. 34, no. 8, pp. 2655-2660, 1995.

[21] G. Pigorini and M. D. LeVan, "Equilibrium theory for pressure swing adsorption. 2: purification and enrichment in layered beds," Industrial and Engineering Chemistry Research, vol. 36, no. 6, pp. 2296-2305, 1997.

[22] G. Pigorini and M. D. LeVan, "Equilibrium theory for pressure swing adsorption. 3: separation and purification in two-component adsorption," Industrial and Engineering Chemistry Research, vol. 36, no. 6, pp. 2306-2319, 1997.

[23] G. Pigorini and M. D. LeVan, "Equilibrium theory for pressure-swing adsorption. 4: optimizations for trace separation and purification in two-component adsorption," Industrial and Engineering Chemistry Research, vol. 37, no. 6, pp. 2516-2528, 1998.

[24] A. Serbezov and S. V. Sotirchos, "Semianalytical solution for multicomponent pressure swing adsorption," Chemical Engineering Science, vol. 53, no. 20, pp. 3521-3536, 1998.

[25] A. Serbezov, "Effect of the process parameters on the lenght of the mass transfer zone during product withdrawal in pressure swing adsorption cycles," Chemical Engineering Science, vol. 56, no. 15, pp. 4673-4684, 2001.

[26] A. D. Ebner and J. A. Ritter, "Equilibrium theory analysis of rectifying PSA for heavy component production," AIChE Journal, vol. 48, no. 8, pp. 1679-1691, 2002.

[27] A. D. Ebner and J. A. Ritter, "Equilibrium theory analysis of dual reflux PSA for separation of a binary mixture," AIChE Journal, vol. 50, no. 10, pp. 2418-2429, 2004.

[28] H. W. Habgood, "The kinetics of molecular sieve action: sorption of nitrogen-methane mixtures by Linde Molecular Sieve 4A," Canadian Journal of Chemistry, vol. 36, pp. 13841397, 1958.

[29] K. Chihara, M. Suzuki, and K. Kawazoe, "Adsorption rate on molecular sieving carbon by chromatography," AIChE Journal, vol. 24, no. 2, pp. 237-246, 1978.

[30] H. Jüntgen, K. Knoblauch, and K. Harder, "Carbon molecular sieves: production from coal and application in gas separation," Fuel, vol. 60, no. 9, pp. 817-822, 1981.

[31] A. Kapoor and R. T. Yang, "Kinetic separation of methanecarbon dioxide mixture by adsorption on molecular sieve carbon," Chemical Engineering Science, vol. 44, no. 8, pp. 1723-1733, 1989.

[32] R. Ramachandran, L. H. Dao, and B. Brooks, "Method of producing unsaturated hydrocarbons and separating the same from saturated hydrocarbons," U.S. patent 5, 365, 011, 1994.

[33] A. I. Fatehi, K. F. Loughlin, and M. M. Hassan, "Separation of methane-nitrogen mixtures by pressure swing adsorption using a carbon molecular sieve," Gas Separation and Purification, vol. 9, no. 3, pp. 199-204, 1995. 
[34] M. W. Seery, "Bulk separation of carbon dioxide from methane using natural clinoptilolite," World Patent, WO 98/58726, 1998.

[35] S. M. Kuznicki, V. A. Bell, I. Petrovic, and P. W. Blosser, "Separation of nitrogen from mixtures thereof with methane utilizing barium exchanged ETS-4," US patent no. 5, 989, 316, 1999.

[36] J. Padin, S. U. Rege, R. T. Yang, and L. S. Cheng, "Molecular sieve sorbents for kinetic separation of propane/propylene," Chemical Engineering Science, vol. 55, no. 20, pp. 4525-4535, 2000.

[37] M. Mitariten, "New technology improves nitrogen-removal economics," Oil and Gas Journal, vol. 99, no. 17, pp. 42-44, 2001.

[38] A. Jayaraman, A. S. Chiao, J. Padin, R. T. Yang, and C. L. Munson, "Kinetic separation of methane/carbon dioxide by molecular sieve carbons," Separation Science and Technology, vol. 37, no. 11, pp. 2505-2528, 2002.

[39] W. B. Dolan and M. J. Mitariten, "Heavy hydrocarbon recovery from pressure swing adsorption unit tail gas," 2003, US patent 6, 610, 124 .

[40] W. B. Dolan and M. J. Mitariten, " $\mathrm{CO}_{2}$ rejection from natural gas," US patent 2003/0047071, 2003.

[41] S. M. Kuznicki and V. A. Bell, "Olefin separation employing ETS molecular sieves," U.S. patent, 6, 517, 611, 2003.

[42] M. B. Kim, Y. S. Bae, D. K. Choi, and C. H. Lee, "Kinetic separation of landfill gas by a two-bed pressure swing adsorption process packed with carbon molecular sieve: nonisothermal operation," Industrial and Engineering Chemistry Research, vol. 45, no. 14, pp. 5050-5058, 2006.

[43] S. Cavenati, C. A. Grande, F. V. S. Lopes, and A. E. Rodrigues, "Adsorption of small molecules on alkali-earth modified titanosilicates," Microporous and Mesoporous Materials, vol. 121, no. 1-3, pp. 114-120, 2009.

[44] D. B. Shah, S. P. Perera, and B. D. Crittenden, "Adsorption dynamics in a monolithic adsorbent," in Fundamentals of Adsorption, M. D. LeVan, Ed., Kluwer Academic Publishers, Boston, Mass, USA, 1996.

[45] K. P. Gadkaree, "System and method for adsorbing contaminants and regenerating the adsorber," U.S. patent 5, 658, 372, 1997.

[46] Y. Y. Li, S. P. Perera, and B. D. Crittenden, “Zeolite monoliths for air separation-part 2: oxygen enrichment, pressure drop and pressurization," Chemical Engineering Research and Design, vol. 76, no. 8, pp. 931-941, 1998.

[47] R. Jain, A. I. LaCava, A. Maheshwary, J. R. Ambriano, D. R. Acharya, and F. R. Fitch, "Air separation using monolith adsorbent bed," U. S. patent, 6, 231, 644, 2001.

[48] R. E. Critoph, "Multiple bed regenerative adsorption cycle using the monolithic carbon-ammonia pair," Applied Thermal Engineering, vol. 22, no. 6, pp. 667-677, 2002.

[49] D. J. Kim, J. W. Kim, J. E. Yie, and H. Moon, “Temperatureprogrammed adsorption and characteristics of honeycomb hydrocarbon adsorbers," Industrial and Engineering Chemistry Research, vol. 41, no. 25, pp. 6589-6592, 2002.

[50] T. Valdés-Solís, M. J. G. Linders, F. Kapteijn, G. Marbán, and A. B. Fuertes, "Adsorption and breakthrough performance of carbon-coated ceramic monoliths at low concentration of n-butane," Chemical Engineering Science, vol. 59, no. 13, pp. 2791-2800, 2004.

[51] A. B. Gorbach, M. Stegmaier, G. Eigenberger, J. Hammer, and H. G. Fritz, "Compact pressure swing adsorption processes-impact and potential of new-type adsorbentpolymer monoliths," Adsorption, vol. 11, no. 1, pp. 515-520, 2005.

[52] C. A. Grande, S. Cavenati, P. Barcia, J. Hammer, H. G. Fritz, and A. E. Rodrigues, "Adsorption of propane and propylene in zeolite 4A honeycomb monolith," Chemical Engineering Science, vol. 61, no. 10, pp. 3053-3063, 2006.

[53] I. Perdana, D. Creaser, I. Made Bendiyasa, Rochmadi, and B. Wikan Tyoso, "Modelling $\mathrm{NO}_{\mathrm{x}}$ adsorption in a thin NaZSM5 film supported on a cordierite monolith," Chemical Engineering Science, vol. 62, no. 15, pp. 3882-3893, 2007.

[54] F. Rezaei and P. Webley, "Optimum structured adsorbents for gas separation processes," Chemical Engineering Science, vol. 64, no. 24, pp. 5182-5191, 2009.

[55] D. M. Ruthven, S. Farooq, and K. S. Knaebel, Pressure Swing Adsorption, VCH Publishers, New York, NY, USA, 1994.

[56] D. Tondeur and P. C. Wankat, "Gas purification by PSA," Separation and Purification Methods, vol. 14, no. 2, pp. 157212, 1985.

[57] C. W. Skarstrom, "Method and apparatus for fractionating gas mixtures by adsorption," U.S. patent 2, 944, 627, 1960.

[58] S. Sircar, "Separation of multicomponent gas mixtures," U.S. patent 4, 171, 206, 1979.

[59] P. Cen and R. T. Yang, "Separation of a five-component gas mixture by pressure swing adsorption," Separation Science and Technology, vol. 20, no. 9-10, pp. 725-747, 1985.

[60] S. Sircar, "Fractionation of multicomponent gas mixtures by pressure swing adsorption,” U.S. patent 4, 790, 858, 1988.

[61] T. C. Golden, R. Kumar, and W. C. Kratz, "Hydrogen purification," US patent 4, 957, 514, 1990.

[62] R. Kumar, "Adsorption process for recovering two high purity gas products from multicomponent gas mixtures," U.S. patent 4, 913, 709, 1990.

[63] O. Bomard, J. Jutard, S. Moreau, and X. Vigor, "Method for purifying hydrogen based gas mixtures using a lithiumexchanged X zeolite," W.O. Patent 97/45363, 1997.

[64] A. Malek and S. Farooq, "Hydrogen purification from refinery fuel gas by pressure swing adsorption," AIChE Journal, vol. 44, no. 9, pp. 1985-1992, 1998.

[65] J. Stöcker, M. Whysall, and G. Q. Miller, 30 Years of PSA Technology for Hydrogen Purification, UOP LLC, Des Plaines, Ill, USA, 1998.

[66] C. H. Lee, J. Yang, and H. Ahn, "Effects of carbon-to-zeolite ratio on layered bed $\mathrm{H}_{2}$ PSA for coke oven gas," AIChE Journal, vol. 45, no. 3, pp. 535-545, 1999.

[67] S. Sircar, W. E. Waldron, M. B. Rao, and M. Anand, "Hydrogen production by hybrid SMR-PSA-SSF membrane system," Separation and Purification Technology, vol. 17, no. 1, pp. 11-20, 1999.

[68] J. H. Park, J. N. Kim, and S. H. Cho, "Performance analysis of four-bed $\mathrm{H}_{2}$ PSA process using layered beds," AIChE Journal, vol. 46, no. 4, pp. 790-802, 2000.

[69] S. Sircar and T. C. Golden, "Purification of hydrogen by pressure swing adsorption," Separation Science and Technology, vol. 35, no. 5, pp. 667-687, 2000.

[70] J. G. Jee, M. B. Kim, and C. H. Lee, "Adsorption characteristics of hydrogen mixtures in a layered bed: binary, ternary, and five-component mixtures," Industrial and Engineering Chemistry Research, vol. 40, no. 3, pp. 868-878, 2001.

[71] M. S. A. Baksh, M. W. Ackley, and F. Notaro, "Process and apparatus for hydrogen purification," W.O. Patent 2004/058630, 2004. 
[72] R. L. Bec, "Method for purifying hydrogen-based gas mixtures using calcium X-zeolite," U.S. patent 6, 849, 106, 2005.

[73] P. Guerin de Montgareuil and D. Domine, "Process for separating a binary gaseous mixture by adsorption," US patent 3, 155, 468, 1964.

[74] N. H. Berlin, "Method for providing an oxygen-enriched environment," U.S. Patent 3, 280, 536, 1966.

[75] H. Jüntgen, K. Knoblauch, J. Reichenberger, and F. Tarnow, "Process for the recovery of nitrogen-rich gases from gases containing at least oxygen as other component," U.S. patent 4, 264, 339, 1981.

[76] D. M. Ruthven, N. S. Raghavan, and M. M. Hassan, "Adsorption and diffusion of nitrogen and oxygen in a carbon molecular sieve," Chemical Engineering Science, vol. 41, no. 5, pp. 1325-1332, 1986.

[77] C. G. Coe, J. F. Kirner, R. Pierantozzi, and T. R. White, "Nitrogen adsorption with $\mathrm{Ca}$ and or $\mathrm{Sr}$ exchanged lithium X-zeolites," U.S. patent 5, 152, 813, 1992.

[78] J. G. Jee, J. S. Lee, and C. H. Lee, "Air separation by a small-scale two-bed medical $\mathrm{O}_{2}$ pressure swing adsorption," Industrial and Engineering Chemistry Research, vol. 40, no. 16, pp. 3647-3658, 2001.

[79] Y. Lü, S. J. Doong, and M. Bülow, “Pressure-swing adsorption using layered adsorbent beds with different adsorption properties: II-experimental investigation," Adsorption, vol. 10, no. 4, pp. 267-275, 2005.

[80] J. C. Santos, A. F. Portugal, F. D. Magalhães, and A. Mendes, "Optimization of medical PSA units for oxygen production," Industrial and Engineering Chemistry Research, vol. 45, no. 3, pp. 1085-1096, 2006.

[81] K. G. Teague and T. F. Edgar, "Predictive dynamic model of a small pressure swing adsorption air separation unit," Industrial and Engineering Chemistry Research, vol. 38, no. 10, pp. 3761-3775, 1999.

[82] K. T. Chue, J. N. Kim, Y. J. Yoo, S. H. Cho, and R. T. Yang, "Comparison of activated carbon and zeolite $13 \mathrm{X}$ for $\mathrm{CO}_{2}$ recovery from flue gas by pressure swing adsorption," Industrial and Engineering Chemistry Research, vol. 34, no. 2, pp. 591-598, 1995.

[83] J. H. Park, H. T. Beum, J. N. Kim, and S. H. Cho, "Numerical analysis on the power consumption of the PSA process for recovering $\mathrm{CO}_{2}$ from flue gas," Industrial and Engineering Chemistry Research, vol. 41, no. 16, pp. 4122-4131, 2002.

[84] A. L. Chaffee, G. P. Knowles, Z. Liang, J. Zhang, P. Xiao, and P. A. Webley, " $\mathrm{CO}_{2}$ capture by adsorption: materials and process development," International Journal of Greenhouse Gas Control, vol. 1, no. 1, pp. 11-18, 2007.

[85] J. S. D'amico, H. E. Reinhold III, and K. S. Knaebel, "Helium recovery," U.S. patent, 5, 542, 966, 1996.

[86] N. K. Das, H. Chaudhuri, R. K. Bhandari, D. Ghose, P. Sen, and B. Sinha, "Purification of helium from natural gas by pressure swing adsorption," Current Science, vol. 95, no. 12, pp. 1684-1687, 2008.

[87] A. P. G. Taveira and A. M. M. Mendes, "Xenon external recycling unit for recovery, purification and reuse of xenon in anesthesia circuits," U.S. patent 7, 442, 236, 2008.

[88] S. Sircar and W. R. Kock, "Adsorptive separation of methane and carbon dioxide gas mixtures," European patent EP, $0193716,1986$.

[89] S. Sircar, "High efficiency separation of methane and carbon dioxide mixtures by adsorption: adsorption and ion exchange," AIChE Symposium Series, vol. 84, pp. 70-72, 1988.
[90] S. Sircar, R. Kumar, W. R. Koch, and J. Vansloun, "Recovery of methane from landfill gas," United States patent 4, 770, 676, 1988.

[91] M. M. Davis, R. L. J. Gray, and K. Patei, "Process for the purification of natural gas," US patent, 5, 174, 796, 1992.

[92] M. Mitariten, "Economic $\mathrm{N}_{2}$ removal," Hydrocarbon Engineering, vol. 9, no. 7, pp. 53-57, 2004.

[93] I. A. A. C. Esteves and J. P. B. Mota, "Simulation of a new hybrid membrane/pressure swing adsorption process for gas separation," Desalination, vol. 148, no. 17-3, pp. 275-280, 2002.

[94] K. S. Knaebel and H. E. Reinhold, "Landfill gas: from rubbish to resource," Adsorption, vol. 9, no. 1, pp. 87-94, 2003.

[95] C. A. Grande and A. E. Rodrigues, "Biogas to fuel by vacuum pressure swing adsorption I. Behavior of equilibrium and kinetic-based adsorbents," Industrial and Engineering Chemistry Research, vol. 46, no. 13, pp. 4595-4605, 2007.

[96] C. A. Grande and R. Blom, "Utilization of Dual-PSA technology for natural gas upgrading and integrated $\mathrm{CO}_{2}$ capture," Energy Procedia, vol. 26, pp. 2-14, 2012.

[97] “Isosiv process operates commercially," Chemical \& Engineering News, vol. 40, pp. 59-63, 1962.

[98] T. C. Holcombe, "N-paraffin-isoparaffin separation process," U.S. patent, 4, 176, 053, 1979.

[99] J. A. C. Silva, Separation of n/iso-paraffins by adsorption process [Ph.D. dissertation], University of Porto, Porto, Portugal, 1998.

[100] A. Mersmann, B. Fill, R. Hartmann, and S. Maurer, "The potential of energy saving by gas phase adsorption processes," Chemical Engineering \& Technology, vol. 23, pp. 937-944, 2000.

[101] S. Sircar, "Pressure swing adsorption," Industrial and Engineering Chemistry Research, vol. 41, no. 6, pp. 1389-1392, 2002.

[102] C. Voss, "Applications of pressure swing adsorption technology," Adsorption, vol. 11, no. 1, pp. 527-529, 2005.

[103] K. Knaebel, "Adsorbent selection," 2004, http://www.adsorption.com/publications/AdsorbentSel1B.pdf.

[104] N. Sundaram and R. T. Yang, "On the pseudomultiplicity of pressure swing adsorption periodic states," Industrial and Engineering Chemistry Research, vol. 37, no. 1, pp. 154-158, 1998.

[105] W. A. Patrick, B. F. Lovelace, and E. B. Miller, "Method and apparatus for separating vapors and gases," U.S. patent 1,335, 348, 1920.

[106] A. B. Ray, "Process of recovering absorbable constituents from gas streams," U.S. patent 1, 548, 280, 1925.

[107] R. T. Yang and P. L. Cen, "Improved pressure swing adsorption processes for gas separation: by heat exchange between adsorbers and by high-heat-capacity inert additives," Industrial \& Engineering Chemistry Process Design and Development, vol. 25, no. 1, pp. 54-59, 1986.

[108] H. Ahn, C. H. A. Lee, B. Seo, J. Yang, and K. Baek, "Backfill cycle of a layered bed $\mathrm{H}_{2}$ PSA process," Adsorption, vol. 5, no. 4, pp. 419-433, 1999.

[109] W. D. Marsh, F. S. Pramuk, R. C. Hoke, and C. W. Skarstrom, "Pressure equalization depressurising in heatless adsorption," U.S. patent no. 3, 142, 547, 1964.

[110] T. M. Stark, "Gas separation by adsorption process," U.S. patent 3, 252, 268, 1966.

[111] M. P. S. Santos, C. A. Grande, and A. E. Rodrigues, "Pressure swing adsorption for biogas upgrading: effect of recycling 
streams in pressure swing adsorption design," Industrial and Engineering Chemistry Research, vol. 50, no. 2, pp. 974-985, 2011.

[112] K. Warmuzinski, "Effect of pressure equalization on power requirements in PSA systems," Chemical Engineering Science, vol. 57, no. 8, pp. 1475-1478, 2002.

[113] J. A. Delgado and A. E. Rodrigues, "Analysis of the boundary conditions for the simulation of the pressure equalization step in PSA cycles," Chemical Engineering Science, vol. 63, no. 18, pp. 4452-4463, 2008.

[114] J. L. Wagner, “Selective adsorption process," U.S. patent no. 3, 430, 418, 1969.

[115] J. Xu, D. L. Rarig, T. A. Cook, K. K. Hsu, M. Schoonover, and R. Agrawal, "Pressure swing adsorption process with reduced pressure equalization time," US patent 6, 565, 628, 2003.

[116] J. Xu and E. L. Weist Jr., "Six bed pressure swing adsorption process with four steps of pressure equalization," US patent $6,454,838,2002$.

[117] N. Casas, J. Schell, and M. Mazzotti, "Pre-combustion $\mathrm{CO}_{2}$ capture by PSA for IGCC plants," in Proceedings of the 10th International Conference on Fundamentals of Adsorption (FOA '10), Awaji, Japan, May 2010.

[118] F. V. S. Lopes, C. A. Grande, and A. E. Rodrigues, "Activated carbon for hydrogen purification by pressure swing adsorption: multicomponent breakthrough curves and PSA performance," Chemical Engineering Science, vol. 66, no. 3, pp. 303-317, 2011.

[119] A. Fuderer, "Pressure swing adsorption with intermediate product recovery," US patent 4, 512, 780, 1985.

[120] R. Ramachandran and L. H. Dao, "Process for recovering alkenes from cracked hydrocarbon streams," US patent 5, 744, 687, 1998.

[121] F. A. Da Silva and A. E. Rodrigues, "Propylene/propane separation by vacuum swing adsorption using $13 \mathrm{X}$ zeolite," AIChE Journal, vol. 47, no. 2, pp. 341-357, 2001.

[122] C. A. Grande and A. E. Rodrigues, "Propane/propylene separation by pressure swing adsorption using zeolite 4A," Industrial and Engineering Chemistry Research, vol. 44, no. 23, pp. 8815-8829, 2005.

[123] A. D. Ebner, J. A. Ritter, M. D. LeVan, and J. C. Knox, "Unique regeneration steps for the sorbent-based atmosphere revitalization system designed for $\mathrm{CO}_{2}$ and $\mathrm{H}_{2} \mathrm{O}$ removal from spacecraft cabins," SAE International Journal of Aerospace, vol. 4, no. 1, pp. 488-493, 2011.

[124] M. Yoshida, J. A. Ritter, A. Kodama, M. Goto, and T. Hirose, "Simulation of an enriching reflux PSA process with parallel equalization for concentrating a trace component in air," Industrial and Engineering Chemistry Research, vol. 45, no. 18, pp. 6243-6250, 2006.

[125] K. P. Kostroski and P. C. Wankat, "High recovery cycles for gas separations by pressure-swing adsorption," Industrial and Engineering Chemistry Research, vol. 45, no. 24, pp. 81178133, 2006.

[126] F. Dong, H. Lou, A. Kodama, M. Goto, and T. Hirose, "A new concept in the design of pressure-swing adsorption processes for multicomponent gas mixtures," Industrial and Engineering Chemistry Research, vol. 38, no. 1, pp. 233-239, 1999.

[127] F. Dong, H. Lou, A. Kodama, M. Goto, and T. Hirose, "The Petlyuk PSA process for the separation of ternary gas mixtures: exemplification by separating a mixture of $\mathrm{CO}_{2}$ $\mathrm{CH}_{4}-\mathrm{N}_{2}$," Separation and Purification Technology, vol. 16, no. 2, pp. 159-166, 1999.
[128] D. Basmadjian and A. L. Pogorski, "Process for the separation of gases by adsorption," US patent 3, 279, 153, 1966.

[129] T. Tamura, "Absorption process for gas separation," US patent 3, 797, 201, 1974.

[130] D. Diagne, M. Goto, and T. Hirose, "Parametric studies on $\mathrm{CO}_{2}$ separation and recovery by a dual reflux PSA process consisting of both rectifying and stripping sections," Industrial and Engineering Chemistry Research, vol. 34, no. 9, pp. 3083-3089, 1995.

[131] B. K. Na, H. Lee, K. K. Koo, and H. K. Song, "Effect of rinse and recycle methods on the pressure swing adsorption process to recover $\mathrm{CO}_{2}$ from power plant flue gas using activated carbon," Industrial and Engineering Chemistry Research, vol. 41, no. 22, pp. 5498-5503, 2002.

[132] S. P. Reynolds, A. D. Ebner, and J. A. Ritter, "Stripping PSA cycles for $\mathrm{CO}_{2}$ recovery from flue gas at high temperature using a hydrotalcite-like adsorbent," Industrial and Engineering Chemistry Research, vol. 45, no. 12, pp. 4278-4294, 2006.

[133] D. M. Ruthven, "PSA discussion," Studies in Surface Science and Catalysis, vol. 80, pp. 788-793, 1993.

[134] R. Rota and P. C. Wankat, "Intensification of pressure swing adsorption processes," AIChE Journal, vol. 36, no. 9, pp. 1299-1312, 1990.

[135] M. Whysall and L. J. M. Wagemans, "Very large-scale pressure swing adsorption processes," US patent 6, 210, 466, 2001.

[136] W. D. Breck, Zeolite Molecular Sieves, John Wiley \& Sons, New York, NY, USA, 1974.

[137] J. E. Martin, M. T. Anderson, J. Odinek, and P. Newcomer, "Synthesis of periodic mesoporous silica thin films," Langmuir, vol. 13, no. 15, pp. 4133-4141, 1997.

[138] D. Zhao, J. Feng, Q. Huo et al., "Triblock copolymer syntheses of mesoporous silica with periodic 50 to 300 angstrom pores," Science, vol. 279, no. 5350, pp. 548-552, 1998.

[139] J. Rocha and M. W. Anderson, "Microporous titanosilicates and other novel mixed octahedral-tetrahedral framework oxides," European Journal of Inorganic Chemistry, no. 5, pp. 801-818, 2000.

[140] S. Reyes, V. V. Krishnan, G. J. De Martin, J. H. Sinfelt, K. G. Strohmaier, and J. G. Santiesteban, "Separation of propylene from hydrocarbon mixtures," International patent, WO 03/080548 A1, 2003.

[141] M. E. Rivera-Ramos, G. J. Ruiz-Mercado, and A. J. Hernández-Maldonado, "Separation of $\mathrm{CO}_{2}$ from light gas mixtures using ion-exchanged silicoaluminophosphate nanoporous sorbents," Industrial and Engineering Chemistry Research, vol. 47, no. 15, pp. 5602-5610, 2008.

[142] F. Rodríguez-Reinoso, M. Molina-Sabio, and M. T. González, "The use of steam and $\mathrm{CO}_{2}$ as activating agents in the preparation of activated carbons," Carbon, vol. 33, no. 1, pp. 15-23, 1995.

[143] Z. Liu, L. Ling, W. Qiao, and L. Liu, "Preparation of pitchbased spherical activated carbon with developed mesopore by the aid of ferrocene," Carbon, vol. 37, no. 4, pp. 663-667, 1999.

[144] S. Jun, Sang Hoon Joo, R. Ryoo et al., "Synthesis of new, nanoporous carbon with hexagonally ordered mesostructure," Journal of the American Chemical Society, vol. 122, no. 43, pp. 10712-10713, 2000.

[145] T. C. Golden, C. M. A. Golden, and D. P. Zwilling, "Selfsupported structured adsorbent for gas separation," US patent $6,565,627,2003$.

[146] J. L. C. Rowsell and O. M. Yaghi, "Metal-organic frameworks: a new class of porous materials," Microporous and Mesoporous Materials, vol. 73, no. 1-2, pp. 3-14, 2004. 
[147] P. D. C. Dietzel, Y. Morita, R. Blom, and H. Fjellvåg, "An in situ high-temperature single-crystal investigation of a dehydrated metal-organic framework compound and fieldinduced magnetization of one-dimensional metal-oxygen chains," Angewandte Chemie-International Edition, vol. 44, no. 39, pp. 6354-6358, 2005.

[148] U. Mueller, M. Schubert, F. Teich, H. Puetter, K. SchierleArndt, and J. Pastré, "Metal-organic frameworksprospective industrial applications," Journal of Materials Chemistry, vol. 16, no. 7, pp. 626-636, 2006.

[149] S. Ma, D. Sun, X. S. Wang, and H. C. Zhou, "A meshadjustable molecular sieve for general use in gas separation," Angewandte Chemie-International Edition, vol. 46, no. 14, pp. 2458-2462, 2007.

[150] S. Cavenati, C. A. Grande, A. E. Rodrigues, C. Kiener, and U. Müller, "Metal organic framework adsorbent for biogas upgrading," Industrial and Engineering Chemistry Research, vol. 47, no. 16, pp. 6333-6335, 2008.

[151] J. H. Cavka, S. Jakobsen, U. Olsbye et al., "A new zirconium inorganic building brick forming metal organic frameworks with exceptional stability," Journal of the American Chemical Society, vol. 130, no. 42, pp. 13850-13851, 2008.

[152] D. P. Valenzuela and A. L. Myers, Adsorption Equilibrium Data Handbook, Prentice Hall, New Jersey, NJ, USA, 1989.

[153] R. T. Yang, Adsorbents. Fundamentals and Applications, John Wiley \& Sons, New Jersey, NJ, USA, 2003.

[154] G. Klein and T. Vermeulen, "Cyclic performance of layered beds for binary ion exchange," AIChE Symposium Series, vol. 71, no. 15, pp. 69-76, 1975.

[155] M. Chlendi and D. Tondeur, "Dynamic behaviour of layered columns in pressure swing adsorption," Gas Separation and Purification, vol. 9, no. 4, pp. 231-242, 1995.

[156] C. F. Watson, R. D. Whitley, and M. L. Meyer, "Multiple zeolite adsorbent layers in oxygen separation," US patent 5, 529, 610, 1996.

[157] J. H. Park, J. N. Kim, S. H. Cho, J. D. Kim, and R. T. Yang, "Adsorber dynamics and optimal design of layered beds for multicomponent gas adsorption," Chemical Engineering Science, vol. 53, no. 23, pp. 3951-3963, 1998.

[158] J. Yang and C. H. Lee, "Adsorption dynamics of a layered bed PSA for $\mathrm{H}_{2}$ recovery from coke oven gas," AIChE Journal, vol. 44, no. 6, pp. 1325-1334, 1998.

[159] Y. Lü, S. J. Doong, and M. Bülow, “Pressure-swing adsorption using layered adsorbent beds with different adsorption properties: I-results of process simulation," Adsorption, vol. 9, no. 4, pp. 337-347, 2003.

[160] S. Cavenati, C. A. Grande, and A. E. Rodrigues, "Separation of $\mathrm{CH}_{4} / \mathrm{CO}_{2} / \mathrm{N}_{2}$ mixtures by layered pressure swing adsorption for upgrade of natural gas," Chemical Engineering Science, vol. 61, no. 12, pp. 3893-3906, 2006.

[161] C. A. Grande and A. E. Rodrigues, "Layered vacuum pressure-swing adsorption for biogas upgrading," Industrial and Engineering Chemistry Research, vol. 46, no. 23, pp. 7844$7848,2007$.

[162] C. A. Grande, S. Cavenati, and A. E. Rodrigues, "Separation column and pressure swing adsorption process for gas purification," World Patent Application, 2008/072215, 2008.

[163] S. N. Vyas, S. R. Patwardhan, S. Vijayalakshmi, and K. S. Ganesh, "Adsorption of gases on carbon molecular sieves," Journal of Colloid And Interface Science, vol. 168, no. 2, pp. 275-280, 1994.

[164] R. Srinivasan, S. R. Auvil, and J. M. Schork, "Mass transfer in carbon molecular sieves-an interpretation of Langmuir kinetics," The Chemical Engineering Journal, vol. 57, no. 2, pp. 137-144, 1995.

[165] S. Farooq, H. Qinglin, and I. A. Karimi, "Identification of transport mechanism in adsorbent micropores from column dynamics," Industrial and Engineering Chemistry Research, vol. 41, no. 5, pp. 1098-1106, 2002.

[166] H. Qinglin, S. M. Sundaram, and S. Farooq, "Revisiting transport of gases in the micropores of carbon molecular sieves," Langmuir, vol. 19, no. 2, pp. 393-405, 2003.

[167] D. Shen, M. Bülow, and N. O. Lemcoff, "Mechanisms of molecular mobility of oxygen and nitrogen in carbon molecular sieves," Adsorption, vol. 9, no. 4, pp. 295-302, 2003.

[168] M. W. Ackley and R. T. Yang, "Diffusion in ion-exchanged clinoptilolites," AIChE Journal, vol. 37, no. 11, pp. 16451656, 1991.

[169] L. Predescu, F. H. Tezel, and S. Chopra, "Adsorption of nitrogen, methane, carbon monoxide, and their binary mixtures on aluminophosphate molecular sieves," Adsorption, vol. 3, no. 1, pp. 7-25, 1996.

[170] W. Zhu, F. Kapteijn, J. A. Moulijn, M. C. Den Exter, and J. C. Jansen, "Shape selectivity in adsorption on the all-silica DD3R,” Langmuir, vol. 16, no. 7, pp. 3322-3329, 2000.

[171] D. H. Olson, "Light hydrocarbon separation using 8-member ring zeolites," US patent 6, 488, 741, 2002.

[172] A. Jayaraman, A. J. Hernandez-Maldonado, R. T. Yang, D. Chinn, C. L. Munson, and D. H. Mohr, "Clinoptilolites for nitrogen/methane separation," Chemical Engineering Science, vol. 59, no. 12, pp. 2407-2417, 2004.

[173] J. Gascón, W. Blom, A. van Miltenburg, A. Ferreira, R. Berger, and F. Kapteijn, "Accelerated synthesis of all-silica DD3R and its performance in the separation of propylene/propane mixtures," Microporous and Mesoporous Materials, vol. 115, no. 3, pp. 585-593, 2008.

[174] S. M. Kuznicki, "Preparation of small-pored crystalline titanium molecular sieve zeolites," US patent 4, 938, 939, 1991.

[175] S. M. Kuznicki, V. A. Bell, S. Nair et al., "A titanosilicate molecular sieve with adjustable pores for size-selective adsorption of molecules," Nature, vol. 412, no. 6848, pp. 720 724, 2001.

[176] J. H. Wills, M. Shemaria, and M. J. Mitariten, "Production of pipeline-quality natural gas with the molecular gate $\mathrm{CO}_{2}$ removal process," SPE Production and Facilities, vol. 19, no. 1, pp. 4-8, 2004.

[177] R. P. Marathe, K. Mantri, M. P. Srinivasan, and S. Farooq, "Effect of ion exchange and dehydration temperature on the adsorption and diffusion of gases in ETS-4," Industrial and Engineering Chemistry Research, vol. 43, no. 17, pp. 52815290, 2004.

[178] O. J. Smith IV and A. W. Westerberg, "Mixed-integer programming for pressure swing adsorption cycle scheduling," Chemical Engineering Science, vol. 45, no. 9, pp. 2833-2842, 1990.

[179] S. Farooq, C. Thaeron, and D. M. Ruthven, "Numerical simulation of a parallel-passage piston-driven PSA unit," Separation and Purification Technology, vol. 13, no. 3, pp. 181-193, 1998.

[180] F. A. Da Silva, J. A. Silva, and A. E. Rodrigues, "General package for the simulation of cyclic adsorption processes," Adsorption, vol. 5, no. 3, pp. 229-244, 1999.

[181] L. T. Biegler, L. Jiang, and V. G. Fox, "Recent advances in simulation and optimal design of pressure swing adsorption 
systems," Separation and Purification Reviews, vol. 33, no. 1, pp. 1-39, 2004.

[182] P. A. Webley and J. He, "Fast solution-adaptive finite volume method for PSA/VSA cycle simulation; 1 single step simulation," Computers and Chemical Engineering, vol. 23, no. 11-12, pp. 1701-1712, 2000.

[183] L. Jiang, V. G. Fox, and L. T. Biegler, "Simulation and optimal design of multiple-bed pressure swing adsorption systems," AIChE Journal, vol. 50, no. 11, pp. 2904-2917, 2004.

[184] S. Nilchan and C. C. Pantelides, "On the optimisation of periodic adsorption processes," Adsorption, vol. 4, no. 2, pp. 113-147, 1998.

[185] D. Nikolic, A. Giovanoglou, M. C. Georgiadis, and E. S. Kikkinides, "Generic modeling framework for gas separations using multibed pressure swing adsorption processes," Industrial and Engineering Chemistry Research, vol. 47, no. 9, pp. 3156-3169, 2008.

[186] D. Nikolic, E. S. Kikkinides, and M. C. Georgiadis, "Optimization of multibed pressure swing adsorption processes," Industrial and Engineering Chemistry Research, vol. 48, no. 11, pp. 5388-5398, 2009.

[187] V. Rama Rao, S. Farooq, and W. B. Krantz, "Design of a two-step pulsed pressure-swing adsorption-based oxygen concentrator," AIChE Journal, vol. 56, no. 2, pp. 354-370, 2010 .

[188] N. Sundaram and P. C. Wankat, "Pressure drop effects in the pressurization and blowdown steps of pressure swing adsorption," Chemical Engineering Science, vol. 43, no. 1, pp. 123-129, 1988.

[189] R. Kumar, "Adsorption column blowdown: adiabatic equilibrium model for bulk binary gas mixtures," Industrial and Engineering Chemistry Research, vol. 28, no. 11, pp. 1677$1683,1989$.

[190] Z. P. Lu, J. M. Loureiro, A. E. Rodrigues, and M. D. LeVan, "Pressurization and blowdown of adsorption beds-II. Effect of the momentum and equilibrium relations on isothermal operation," Chemical Engineering Science, vol. 48, no. 9, pp. 1699-1707, 1993.

[191] W. E. Waldron and S. Sircar, "Parametric study of a pressure swing adsorption process," Adsorption, vol. 6, no. 2, pp. 179 $188,2000$.

[192] D. Ko, R. Siriwardane, and L. T. Biegler, "Optimization of a pressure-swing adsorption process using zeolite $13 \mathrm{X}$ for $\mathrm{CO}_{2}$ sequestration," Industrial and Engineering Chemistry Research, vol. 42, no. 2, pp. 339-348, 2003.

[193] A. Agarwal, L. T. Biegler, and S. E. Zitney, "A superstructurebased optimal synthesis of PSA cycles for post-combustion $\mathrm{CO}_{2}$ capteffectively captureure," AIChE Journal, vol. 56, no. 7, pp. 1813-1828, 2010.

[194] K. Ramachandran, S. L. Lerner, and D. L. MacLean, "PSA multicomponent separation utilizing tank equalization," US patent 4, 816, 039, 1989.

[195] A. Mehrotra, A. D. Ebner, and J. A. Ritter, "Arithmetic approach for complex PSA cycle scheduling," Adsorption, vol. 16, no. 3, pp. 113-126, 2010.

[196] A. Mehrotra, A. D. Ebner, and J. A. Ritter, "Simplified graphical approach for complex PSA cycle scheduling," Adsorption, vol. 17, no. 2, pp. 337-345, 2011.

[197] P. H. Turnock and R. H. Kadlec, "Separation of nitrogen and methane via periodic adsorption," AIChE Journal, vol. 17, pp. 335-342, 1971.

[198] R. L. Jones, I. I. Keller, I. I. G. E, and R. C. Wells, "Rapid pressure swing adsorption process with high enrichment factor," US patent 4, 194, 892, 1980.
[199] D. E. Earls and G. N. Long, "Multiple bed rapid pressure swing adsorption for oxygen," US patent 4, 194, 891, 1980.

[200] T. J. Dangieri and R. T. Cassidy, "Enhanced performance in rapid pressure swing adsorption processing," W.O. patent 86/002015, 1986.

[201] S. Sircar, "Gas separation by rapid pressure swing adsorption," US patent 5, 071, 449, 1991.

[202] S. Sircar and B. F. Hanley, "Production of oxygen enriched air by rapid pressure swing adsorption," Adsorption, vol. 1, no. 4, pp. 313-320, 1995.

[203] B. H. L. Betlem, R. W. M. Gotink, and H. Bosch, "Optimal operation of rapid pressure swing adsorption with slop recycling," Computers and Chemical Engineering, vol. 22, supplement 1, pp. S633-S636, 1998.

[204] S. Kulish and R. P. Swank, "Rapid cycle pressure swing adsorption oxygen concentration method and apparatus," US patent 5, 827, 358, 1998.

[205] B. G. Keefer, "High frequency pressure swing adsorption," U.S. Patent 6, 176, 897, 2001.

[206] R. Arvind, S. Farooq, and D. M. Ruthven, "Analysis of a piston PSA process for air separation," Chemical Engineering Science, vol. 57, no. 3, pp. 419-433, 2002.

[207] D. J. Connor, D. G. Doman, L. Jeziorowski et al., "Rotary pressure swing adsorption apparatus," US patent 6, 406, 523, 2002.

[208] T. C. Golden, E. L. Weist Jr., and P. A. Novosat, "Adsorbents for rapid cycle pressure swing adsorption processes," US patent 7, 404, 846, 2008.

[209] E. M. Kopaygorodsky, V. V. Guliants, and W. B. Krantz, "Predictive dynamic model of single-stage ultra-rapid pressure swing adsorption," AIChE Journal, vol. 50, no. 5, pp. 953962, 2004.

[210] R. S. Todd and P. A. Webley, "Mass-transfer models for rapid pressure swing adsorption simulation," AIChE Journal, vol. 52, no. 9, pp. 3126-3145, 2006.

[211] S. Alizadeh-Khiavi, J. A. Sawada, A. C. Gibbs, and J. Alvaji, "Rapid cycle syngas pressure swing adsorption system," US patent application 2007/0125228, 2007.

[212] T. C. Golden and E. L. Weist, "Activated carbon as sole absorbent in rapid cycle hydrogen PSA," US patent 6, 660, 064, 2003.

[213] M. J. LaBuda, T. C. Golden, R. D. Whitley, and C. E. Steigerwalt, "Performance stability in rapid cycle pressure swing adsorption systems," European Patent Application, vol. 1, pp. 917-994, 2008.

[214] N. Sundaram, B. K. Kaul, E. W. Corcoran, C. Y. Sabottke, and R. L. Eckes, "Integration of rapid cycle pressure swing adsorption with refinery process units (hydroprocessing, hydrocracking, etc.)," US patent 7, 591, 879, 2009.

[215] C. Siew-Wah, S. Sircar, and M. V. Kothare, "Miniature oxygen concentrators and methods," US patent 8, 226, 745, 2012.

[216] F. V. S. Lopes, C. A. Grande, and A. E. Rodrigues, "Fastcycling VPSA for hydrogen purification," Fuel, vol. 93, pp. 510-523, 2012.

[217] S. Sircar, "Influence of gas-solid heat transfer on rapid PSA," Adsorption, vol. 11, no. 1, pp. 509-513, 2005.

[218] B. G. Keefer, A. Carel, B. Sellars, I. Shaw, and B. Larisch, "Adsorbent laminate structures," US patent 6, 692, 626, 2004.

[219] B. G. Keefer and C. R. McLean, "High frequency rotary pressure swing adsorption: Apparatus," US patent 6, 056, 804, 2000.

[220] A. S. T. Chiang and M. C. Hong, "Radial flow rapid pressure swing adsorption," Adsorption, vol. 1, no. 2, pp. 153-164, 1995. 
[221] J. Smolarek, F. W. Leavitt, J. J. Nowobilski, V. E. Bergsten, and J. H. Fassbaugh, "Radial bed vaccum/pressure swing adsorber vessel," US patent 5, 759, 242, 1998.

[222] W. C. Huang and C. T. Chou, "Comparison of radialand axial-flow rapid pressure swing adsorption processes," Industrial and Engineering Chemistry Research, vol. 42, no. 9, pp. 1998-2006, 2003.

[223] D. M. Ruthven, "Past progress and future challenges in adsorption research," Industrial and Engineering Chemistry Research, vol. 39, no. 7, pp. 2127-2131, 2000.

[224] P. Xiao, J. Zhang, P. Webley, G. Li, R. Singh, and R. Todd, "Capture of $\mathrm{CO}_{2}$ from flue gas streams with zeolite $13 \mathrm{X}$ by vacuum-pressure swing adsorption," Adsorption, vol. 14, no. 4-5, pp. 575-582, 2008.

[225] S. Dasgupta, N. Biswas, Aarti et al., " $\mathrm{CO}_{2}$ recovery from mixtures with nitrogen in a vacuum swing adsorber using metal organic framework adsorbent: A Comparative Study," The International Journal of Greenhouse Gas Control, vol. 7, pp. 225-229, 2012.

[226] Z. Liu, C. A. Grande, P. Li, J. Yu, and A. E. Rodrigues, "Multi-bed vacuum pressure swing adsorption for carbon dioxide capture from flue gases," Separation and Purification Technology, vol. 81, pp. 307-317, 2011.

[227] C. Shen, Z. Liu, P. Li, and J. Yu, "Two-stage VPSA process for $\mathrm{CO}_{2}$ capture from flue gas using activated carbon," Industrial \& Engineering Chemistry Research, vol. 51, pp. 5011-5021, 2012.

[228] C. A. Grande, F. Poplow, and A. E. Rodrigues, "Vacuum pressure swing adsorption to produce polymer-grade propylene," Separation Science and Technology, vol. 45, no. 9, pp. 12521259, 2010.

[229] M. Tagliabue, D. Farrusseng, S. Valencia et al., "Natural gas treating by selective adsorption: material science and chemical engineering interplay," Chemical Engineering Journal, vol. 155, no. 3, pp. 553-566, 2009.

[230] C. A. Grande and R. Blom, "Utilization of dual-PSA technology for natural gas upgrading and integrated $\mathrm{CO}_{2}$ capture," Energy Procedia, vol. 26, pp. 2-14, 2012.

[231] S. Sircar, "Separation of multicomponent gas mixtures," US patent, 4, 171, 206, 1978.

[232] Y. Chen, A. Kapoor, and R. Ramachandran, "Two stage pressure swing adsorption process," US patent 5, 993, 517, 1999.

[233] Y. Takamura, S. Narita, J. Aoki, S. Hironaka, and S. Uchida, "Evaluation of dual-bed pressure swing adsorption for $\mathrm{CO}_{2}$ recovery from boiler exhaust gas," Separation and Purification Technology, vol. 24, no. 3, pp. 519-528, 2001.

[234] D. L. Rarig, T. C. Golden, and E. L. Weist Jr., "Purification of $\mathrm{CO}_{2}$ from $\mathrm{H}_{2}$ PSA vent gas," in Proceedings of the National AIChE Meeting, Indianapolis, Ind, USA, November 2002.

[235] C. A. Grande and R. Blom, "Dual pressure swing adsorption units for gas separation and purification," Industrial \& Engineering Chemistry Research, vol. 51, pp. 8695-8699, 2012. 

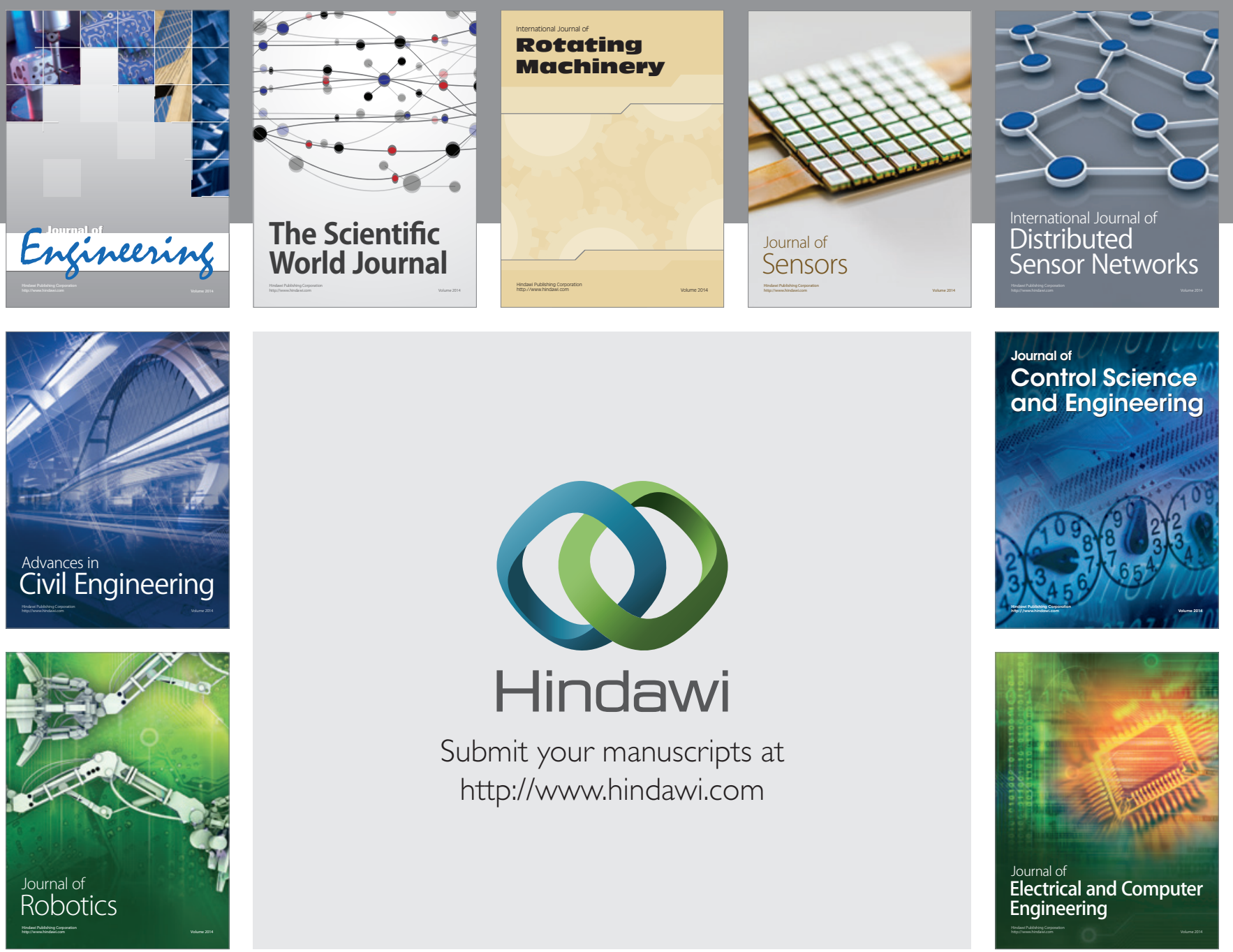

Submit your manuscripts at

http://www.hindawi.com
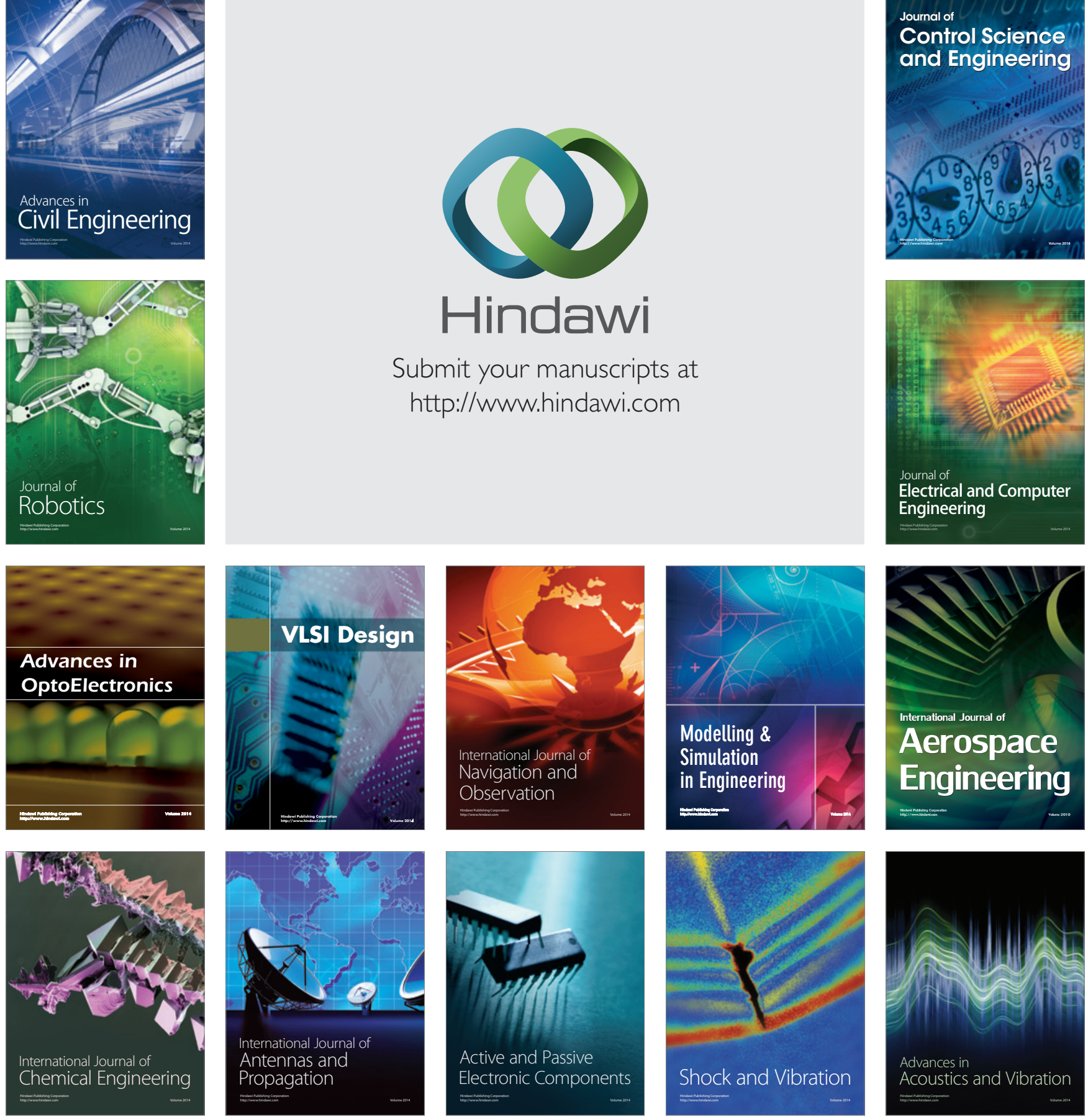